\title{
Obstructive Sleep Apnea: A Dental Perspective
}

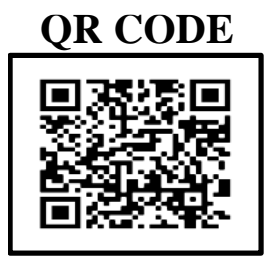

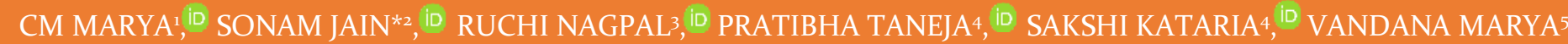

PURPOSE: The present review was conducted to elaborate Obstructive Sleep Apnea (OSA) and the role of dentist in its diagnoses and management.

METHODS: A comprehensive literature search was performed in the electronic databases of PubMed, ScienceDirect and Google scholar. A total of 94 relevant peer reviewed articles were retrieved and 42 were included in the present review.

RESULTS: OSA can be fairly diagnosed by dentists while the patient has come for dental check-up. But insufficient knowledge and awareness among dentists about the diagnostic and treatment protocol of this under-diagnosed condition. It has also proven to be one of the underlying cause of many like diseases like cardiovascular problems, diabetes mellitus and hypertension. To the rescue, dental sleep medicine is gaining enormous attention. In the lieu of the above context 'American Dental Association (ADA)' has adopted a policy that focuses on outlines various diagnostic procedures and treatment modalities that can be carried out by dentist for management of OSA.

CONCLUSION: It can be concluded since there is no sufficient evidence for the prevalence of OSA in developing countries like India, it is needed to create awareness and implement appropriate diagnostic and preventive measures for the same.

KEYWORDS: Dental Sleep Medicine, Obstructive Sleep Apnea, Sleep Apnea, American Dental Association

\section{INTRODUCTION}

"It is a common experience that a problem difficult at night is resolved in the morning after the committee of sleep has worked on it."

\section{- John Steinbeck}

In relation to the above mentioned quote, however, if the quality of sleep is compromised it can have a negative impact on the general health, mental health and social life as well as day to day activities. The troubled sleep if prolongs over a period of time may lead to life threatening disease like diabetes, hypertension, stroke, depression and cardiovascular diseases. ${ }^{1}$ Thus, quality and quantity of sleep is a basic need of humans and is of paramount importance for overall well-being of oneself just like breathing or eating. ${ }^{2}$

Although for an adult 7-9 hours of sleep is recommended, ${ }^{3}$ yet there has been increasing evidence of downward trends in the average duration of sleep and increasingly higher prevalence of sleep disturbances, in western as well as Asia-African countries. ${ }^{4-9}$ Sleep problems remains under represented in many developing countries due to lack of evidence or awareness about the burden of sleep problems.

The most common cause for sleep deprivation is insomnia. It is often associated with a medical or psychiatric problem environmental influence stress or can be idiopathic. ${ }^{10}$ Next to Insomnia comes sleep disordered breathing (SDB) which includes a wide spectrum of sleep-related breathing abnormalities.

Sleep apnea syndrome (SAS) is among them which is characterized by recurring cessations or reduction of breathing while sleeping and thus leading to disruption of sleep. SAS is of 3 types ${ }^{11}$, among which obstructive sleep apnea (OSA) is the most common form. It is characterized by repetitive collapse of the upper airway during sleep, which may be either partial or total resulting in hypopnea (reduction in breathing or airflow to at least $50 \%$ ) or apnea (complete cessation of breathing or airflow for 10 seconds or longer) respectively and occurs more than five times per hour. Apnea-hyponea index (AHI) records number of apneas and hyponeas per hour of 
sleep." OSA along with daytime hypersomnolence which leads to snoring is known as Obstructive sleep apnea syndrome (OSAS) or Obstructive sleep apnea hypopnea syndrome (OSAHS). ${ }^{12}$ It may occur throughout the entire lifespan, from neonates to the elderly, most frequently in middle age (4\%) and increases with age. ${ }^{13}$ The prevalence of OSAS is approximately 3 to $7 \%$ for adult men and 2 to $5 \%$ for adult women in the general population as per the data available from different countries across the world. ${ }^{14-20}$ The impact of OSAS is expected to be huge in developing countries like India as a hike in risk factors like sedentary lifestyle and its potential contribution to the increased rates of cardiovascular diseases, diabetes mellitus and obesity are highly reported. The prevalence of OSAS has been estimated to be $3.6 \%$ in an Indian community based sample translating to over 36 million affected individuals. This result when extrapolated to the overall population counts to one billion in India which makes it a significant public health problem. ${ }^{21}$

Dentists are said to be very well positioned to identify patients at greater risk of OSA and can play an essential role in their multidisciplinary care. Therefore, the present review was carried out to elaborate the role of dentist in diagnosis and management of OSA and its importance in Indian scenario.

\section{METHODS}

A literature search was performed in the electronic databases of PubMed, ScienceDirect and Google scholar. In order to define the keywords for search in databases, few seminal articles were analysed. Data was retrieved by a member of the research team using keywords like "sleep disordered breathing, Obstructive sleep apnea, dental sleep medicine, sleep apnea in dentistry" in multiple combinations were entered into Medical Subject Headings (MeSH) controlled vocabulary. Along with these terms we found additional keywords like sleep apnea/hypoapnea syndrome", "sleep apnea/hyponea syndrome" , "sleep apnea/hypopnea", "sleep apnea/hypopnea episodes", "sleep apnea/hypopnea events", "sleep apnea/hypopnea index" , "sleep apnea/hypopnea patients" as MeSH terms. Relevant terms were combined with the $\mathrm{MeSH}$ terms by Boolean phrases like 'AND' or 'OR' and entered in PubMed, ScienceDirect and Google Scholar. We also made a manual search in the key journals available in the library of the institution. Some data was also obtained by cross checking the reference lists of the articles accessed. Peer reviewed studies which were relevant to the topic and were in English language were selected for the present review. A total of 94 relevant articles were retrieved from which 42 articles were included for the main content of the present review.

\section{PATHOPHYSIOLOGY OF OSA}

Sleep apnea syndrome is of 3 types- central, obstructive and complex or mixed sleep apnea. Central sleep apnea is caused when respiratory control centres in brain temporarily pause the activation of respiratory muscles. Obstructive is characterized by repetitive episodes of complete (apnea) and partial (hyponea) upper airway obstruction during sleep. Combination of both results in complex or mixed sleep apnea." Among them obstructive sleep apnea (OSA) is the most prevalent type. Central sleep apnea is differentiated from obstructive sleep apnea by a lack of respiratory effort in former and continued but ineffective respiratory effort in OSA. ${ }^{12}$ Obstructive sleep apnea can occur during sleep in response to a number of possible physiologic traits or combinations of traits. There can be obstruction or collapse somewhere between the nasal turbinates down to the level of vocal cords or in oropharynx. Most of the time tongue falls back in region oropharynx causing obstruction. This subsequently leads to increased resistance to airflow in the upper respiratory area which can potentially impair the surrounding muscles if the additional pressures persist for longer duration. ${ }^{22}$

\section{CONSEQUENCES OF UNTREATED OBSTRUCTIVE SLEEP APNEA}

I. Excessive day time sleepiness: Automobile and industrial accidents, intellectual deterioration, Personality and behaviour changes, depression, psychosis, deficits in thinking, perception, memory and ability to learn. ${ }^{23}$

II. Cardiovascular System: OSAS is closely related to increase in blood pressure. A study published on 2015 reveals that untreated OSAS patients are in greater risk of having coronary artery disease, stroke and hypertension. ${ }^{24}$

III. Central Nervous System: A number of studies have shown patients with untreated cases of OSAS often report with loss of concentration, frustration and distress due to combination of excessive day 
sleepiness and fragmented sleep during night.. ${ }^{25}$

IV. Endocrine System: A sleep related disorder can lead to insulin resistance and result in diabetes mellitus. ${ }^{26}$

V. Periodontits: Studies has been conducted to assess the association between Periodontitis and OSA with different severity. Findings of these suggested positive influence of OSA on periodontal health, thus causing periodontitis majorly in moderate or severe OSA. ${ }^{27}$

\section{SYMPTOMS OF OSA}

- Cardinal symptoms include loud snoring along with Apnea happening events

- Apnea-hyponea events alone which is also called nocturnal choking

- Excessive daytime sleepiness (EDS) which is called hypersomnolence

- Fatigue, morning headaches lack of concentration, impaired memory, Insomnia and possibly anxiety and depression. ${ }^{25}$

\section{DIAGNOSIS}

Specific tests are required for the establishing the diagnosis of the OSA like polysomnography (PSG) or portable monitoring (PM). These tests are prescribed and interpreted by a medical doctor. PSG score yield AHI scores which divides the OSA into 3 categories depending upon the severity. Among adults, normal AHI normal is $<5$ while mild OSA is considered when AHI score is 5 to 15 , moderate OSA is with 15-30 AHI score and severe OSA is with $>30 \mathrm{AHI}$ score. ${ }^{28}$

\section{ORAL EXAMINATION ${ }^{29}$}

- Hypotonic tongue

- Macroglossy,

- Retrognathic mandible/maxilla,

- Micrognathism,

- V-shaped palate,

- Narrow arches

- Crossbites

- Signs of mouth breathing

\section{RADIOGRAPHIC FEATURES}

Larger distance between the mandibular plane and hyoid bone, posterior displacement of the symphysis ${ }^{14}$ and other disproportionate relationships between the tongue base, soft palate, cranial base, pterygoid processes, cervical spine, and others.

After identifying the potential subject with the disorder, dentist can take a detailed history of the patient including details of snoring, excessive daytime sleepiness (EDS), disturbed sleep at night, difficulties in concentrating or frequently experiencing confusions etc.

Epworth sleepiness scale is a commonly used scale to assess ESS. This screening tool can be easily applied and can be incorporated while taking health of the suspected subjects. A score of 10 or more on this scale indicated presence of ESS. ${ }^{30}$ At the time of presence of positive findings, one should refer the patient to general physician for further diagnosis.

Berlin questionnaire has been successfully used as a screening tool for primary care of the population. ${ }^{31}$ In this survey questions address snoring behavior, EDS/fatigue, and history of obesity or hypertension. The sensitivity of the Berlin questionnaire with regards to high-risk patients having sleep apnea was $86 \%$. Another screening tool called the STOP BANG questionnaire was developed to screen for the most common risk factors seen specifically in OSA. ${ }^{32}$

\section{MANAGEMENT OF OSA}

It can be treated effectively by surgical or nonsurgical methods. An approach to OSAS depends on severity of condition of patient, records of apnea or hypopnea episodes per hour and relationship between OSAS and systemic complications ${ }^{33}$

Non-surgical methods- they can be conservative or mechanical.

\section{Conservative methods ${ }^{33}$}

a) Behavioral changes: Weight loss accompanied by healthy diet will eradicate the problem completely. Also, abstaining from alcohol consumption 3-5 hours before sleep can help in reducing the resistance of upper airway. Nasal dilator strips or sprays can be used to reduce snoring to an extent.

b) Position therapy: Guiding the patient with mild OSA symptoms to sleep sidewise and positioning head at a higher level than the body.

\section{Mechanical methods}

Continuous Positive Airway Pressure (CPAP): CPAP is the most effective treatment for relieving symptoms of moderate to severe cases of OSAS. It is considered to be the gold standard treatment and usually the first line treatment specially in the case of severe OSA. It consists of a mask which the patient has to wear during sleep over the nose or/and mouth. It 
provides steady and continuous air pressure which can be adjusted to prevent the soft tissue in the back of the neck to collapse and cause upper airway obstruction. As this has a bulky apparatus, its compliance among patients is low. ${ }^{34,35}$

III. Surgical methods: These methods include sugeries removing structures that obstruct the airway passage and they are Adenotonsillectomy, Somnoplasty, Uvulopalatopharyngoplasty (UPPP), Maxillomandibular advancement surgeryandNasal surgery..$^{36,37}$

IV. Pharmacotherapy: FDA approved drug for OSA is Modafinil for use in patients with OSA having residual daytime sleepiness. Armodafinil, the Renantiomer of modafinil, is also now a FDA approved for use. Drugs such as tri cyclic antidepressants (Desipramine), Zolpidem, which are serotonergic, noradrenergic and which acts on the potassium channels can improve muscle responsiveness during airway narrowing. ${ }^{37}$

\section{ROLE OF DENTIST IN THE MANAGEMENT OF OSAS}

As dental clinicians see most of their patients every 6 months to 1 year, they can be first line defence in screening and sometimes treating patients with OSA (mild to moderate OSA). ${ }^{22}$ Therefore, dentist can bridge between the undiagnosed portion of population with OSA and field of medicine, thereby aiding in providing appropriate medical care to the subjects affected.

As a dentist one must examine the oropharynx region, tongue, uvula, soft palate and tonsils during clinical evaluation. The tongue volume is determined to indicate the air column obstruction with the help of Mallampatti index. ${ }^{29}$ The shape and volume of uvula and soft palate and position of mandible should be observed vertically and horizontally. It can further be fortified by radiographic examination. ${ }^{38}$

Some of the signs of OSA identified by oral examinations and radiographic images taken in dental settings are listed as follows:-39,40

Taking in account the poor compliance with CPAP, Orthodontic correction with use of oral appliances therapy(OAT) is alternative but effective way of correcting OSAS by advancing the mandible and changing the tongue posture to improve the airflow in upper airway and reduce the incidence of supine apnea. ${ }^{7,23,41}$

\section{Indications of Oral Appliance Therapy (OAT) \\ i. Mild to moderate symptoms of OSAS \\ ii. Low BMI rate \\ iii. $8 \mathrm{~mm}$ or more mandible advancement \\ iv. Intolerance or failure of CPAP therapy \\ v. Patients unwilling for surgery. ${ }^{1,6,7}$}

\section{Contraindications of Oral Appliance Therapy:}

i. TMJ disorders

ii. Limited mandibular movements

iii. Poor oral hygiene

iv. Presence of 6 to 10 teeth or less than in each arch.

v. For behavioral measures such as weight loss or sleep-position change. ${ }^{37,42}$

Type of OAT presently available in the market areMAD (Mandibular advancement devices), TRD (Tongue retaining device), SPL (Soft Palate Lift). ${ }^{33}$ These appliances are given depending upon the case severity and underlying etiology of the patients. Studies have compared different devices according to the severity of OSA. ${ }^{43}$

Thus, Dentists can and do play an essential role in the multidisciplinary care of patients with sleep related breathing disorders. In the lieu of the above context 'American Dental Association (ADA)'has adopted a policy that outlines the role of dentist as given in Table 1.

\section{INDIAN SCENARIO}

Still there is huge number of unmet medical needs concerned with sleep related breathing disorders. The rising awareness about the same has lead to increased rate of screening of the ailment. To the rescue, dental sleep medicine is gaining enormous attention. It is a rapidly growing field working in close approximation with general medicine and further enhancing the timely diagnoses along with appropriate treatment to the patients. ${ }^{45}$

Scenario in India is still grave. So far few prevalence studies in India have been conducted, findings from these suggests high prevalence of OSA. ${ }^{20,21}$ Also ,it is expected that large portion of population is still undiagnosed that can be equivalent to submerged portion of an iceberg. It can be pertained to high cost of equipments, methodologic difficulties and high 


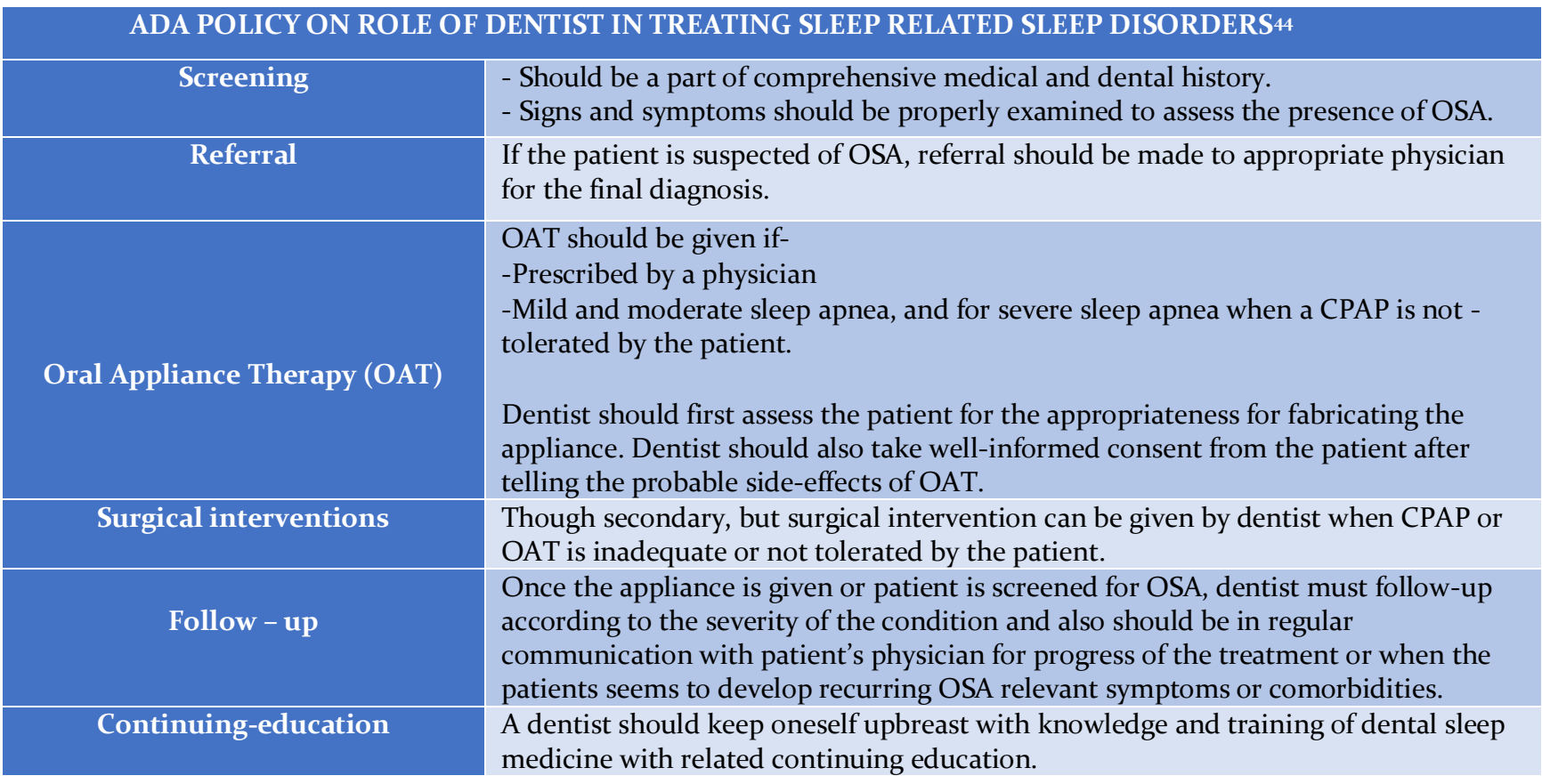

Table 1. ADA Policy on Role of Dentist in Treating Sleep Related Sleep Disorders44

patient load in hospitals. Also, sleep medicine has been slow to develop in India, as there are only 40 sleep laboratories in the country with the population more than 1 billion. ${ }^{46}$ Studies has shown lack of awareness among Indian dentists as well as physicians about prevalence, diagnosis and management of sleep apnea syndrome.47,48 Since India is developing nation, change in lifestyles with urbanisation is affecting the health of the people. As we are having a huge proportion of people with obesity, diabetes and cardiovascular disorders, the impact of undetected OSA as a public health burden cannot be undermined. In the light of evidence available, there is need for implementation of appropriate diagnostic and preventive measures. Also, dental sleep medicine should be incorporated in the curriculum of dental education. This way we can nib this problem in the bud by training the budding dental clinicians. Subsidy on the diagnostic facilities as well as treatment modalities can be another measure to address this problem in under-served areas of India.

\section{CONCLUSION}

From the present review, it can be concluded that being in a position of screening patients more frequently, dentists can aid in much early diagnosis of OSA. This can further prevent the life-threatening complications that may follow this condition. Therefore, dental sleep medicine should be incorporated in the curriculum or continuing dental education (CDE) programs must be organised to prepare dentists to combat this unseen but widely prevalent health problem.

\section{REFERENCES}

1. Riley R, Guilleminault C, Powell N, Simmons FB. Palatopharyngoplasty failure, cephalometric roentgenograms, and obstructive sleep apnea. Otolaryngol Head Neck Surg.1985;93(2):240-44.

2. Grandner MA. Sleep, Health, and Society. Sleep Med Clin. 2016;12(1):1-22.

3. Watson NF, Badr MS, Belenky G, Bliwise DL, Buxton OM, Buysse D et al. Recommended amount of sleep for a healthy adult: a joint consensus statement of the American Academy of Sleep Medicine and Sleep Research Society. 2015; Sleep 38(6):843-44 4. Sutton DA, Moldofsky H, Badley EM. Insomnia and health problems in Canadians. Sleep. 2001; 24:665-70. 5. Groeger JA, Zijlstra FR, Dijk DJ. Sleep quantity, sleep difficulties and their perceived consequences in a representative sample of some 2000 British adults. J Sleep Res. 2004; 13:359-71.

6. Kronholm E, Partonen $\mathrm{T}$, Laatikainen $\mathrm{T}$ et al. Trends in self-reported sleep duration and insomniarelated symptoms in Finland from 1972 to 2005: a 
comparative review and re-analysis of Finnish population samples. J Sleep Res. 2008; 17:54-62.

7. Stranges S, Dorn JM, Shipley MJ, Kandala NB, Trevisan M, Miller MA et al. Correlates of short and long sleep duration: a cross-cultural comparison between the United Kingdom and the United States: the Whitehall II Study and the Western New York Health Study. Am J Epidemiol. 2015;168(12):1353-64.

8. Knutson KL, Van Cauter E, Rathouz PJ, DeLeire T, Lauderdale DS. Trends in the prevalence of short sleepers in the USA: 1975-2006. Sleep. 2010; 33:37-45. 9. Stranges S, Tigbe W, Gómez-Olivé FX, Thorogood M, Kandala NB. Sleep problems:an emerging global epidemic? Findings from the INDEPTH WHO-SAGE study among more than 40,0oo older adults from 8 countries across Africa and Asia. Sleep. 2012; 35(8):1173-81.

10. Li SX, Chan NY, Man Yu MW, Lam SP, Zhang J, Yan Chan JW, Li AM, Wing YK. Eveningness chronotype, insomnia symptoms, and emotional and behavioural problems in adolescents. Sleep Med. 2018; 47:93-99

11. Staner L. Sleep and anxiety disorders. Dialogues Clin Neurosci. 2003; 5(3):249-58.

12. Zhang W, Si LY. Obstructive sleep apnea syndrome (OSAS) and hypertension: pathogenic mechanisms and possible therapeutic approaches. Ups J Med Sci. 2012; 117(4):370-82.

13. Jennum P, Riha RL. Epidemiology of sleep apnoea/hypopnoea syndrome and sleep-disordered breathing. Eur Respir J. 2009; 33(4):907-14.

14. Young T, Palta M, Dempsey J, Skatrud J, Weber S, Badr S. The occurrence of sleep-disordered breathing among middle-aged adults. N Engl J Med. 1993; 328:1230-1235.

15. Bixler EO, Vgontzas AN, Lin HM, Ten Have T, Rein J, Vela-Bueno A, Kales A. Prevalence of sleepdisordered breathing in women: effects of gender. Am J Respir Crit Care Med. 2001; 163:6o8-613

16. Bearpark H, Elliott L, Grunstein R, Cullen S, Schneider H, Althaus W, Sullivan C. Snoring and sleep apnea: a population study in Australian men. Am J Respir Crit Care Med. 1995;151:1459-1465

17. Ip MS, Lam B, Lauder IJ, Tsang KW, Chung KF, Mok YW, Lam WK. A. community study of sleepdisordered breathing in middle-aged Chinese men in Hong Kong. Chest. 2001;119:62-69.

18. Ip MS, Lam B, Tang LC, Lauder IJ, Ip TY, Lam WK. A community study of sleep-disordered breathing in middle-aged Chinese women in Hong Kong: prevalence and gender differences. Chest. 2001;125: 127-134.
19. Kim J, In K, Kim J, You S, Kang K, Shim J, Lee S, Lee J, Lee S, Park C, et al. Prevalence of sleepdisordered breathing in middle-aged Korean men and women. Am J Respir Crit Care Med. 2004; 170: 11081113 .

20. Udwadia ZF, Doshi AV, Lonkar SG, Singh CI. Prevalence of sleepdisordered breathing and sleep apnea in middle-aged urban Indian men. Am J Respir Crit Care Med. 2004; 169:168-173.

21. Sharma SK, Kumpawat S, Banga A, Goel A. Prevalence and risk factors of obstructive sleep apnoea syndrome in a population of Delhi, India. Chest. 2006; 130:149-56.

22. Modesti-Vedolin G, Chies C, Chaves-Fagondes S, Piza-Pelizzer E, Lima-Grossi M. Efficacy of a mandibular advancement intraoral appliance (MOA) for the treatment of obstructive sleep apnea syndrome (OSAS) in pediatric patients: A pilot-study. Med Oral Patol Oral Cir Bucal. 2018; 23(6):e656-e663. 23. Haviv Y, Benoliel R, Bachar G, Michaeli E. On the edge between medicine and dentistry: review of the dentist's role in the diagnosis and treatment of snoring and sleep apnea. Quintessence Int. 2014; 45(4):345-53.

24. Schwarz EI, Puhan MA, Schlatzer C, Stradling JR, Kohler M. Effect of CPAP therapy on endothelial function in obstructive sleep apnoea: A systematic review and meta-analysis. Respirology. 2015; 20(6):889-5.

25. Mbata G, Chukwuka J. Obstructive sleep apnea hypopnea syndrome. Ann Med Health Sci Res.2012; 2(1):74-7.

26. Reichmuth KJ, Austin D, Skatrud JB, Young T. Association of sleep apnea and type II diabetes: A population-based study. Am J RespirCrit Care Med. 2005; 172(12):1590-5.

27. Latorre C, Escobar F, Velosa J, Rubiano D, Hidalgo-Martinez P, Otero L. Association between obstructive sleep apnea and comorbidities with periodontal disease in adults. J Indian Soc Periodontol. 2018; 22(3):215-20.

28. Ruehland W, Rochford P, O'Donoghue $\mathrm{F}$ et al. The new AASM criteria for scoring hypopneas: impact on the apnea hypopnea index. Sleep.2009; 32:150-7.

29. Kumar HV, Schroeder JW, Gang Z, Sheldon SH. Mallampati score and pediatric obstructive sleep apnea. J Clin Sleep Med. 2014; 10(9):985-90.

30. Alencar e Rangel AJ, Barros VM, Seraidarian PI. Snoring and Obstructive Sleep Apnea syndrome: A reflection on the role of Dentistry in the current scientific scenario. Dental Press J Orthod.2012; 17(3): $58-63$. 
31. Ruangsri S, Jorns TP, Puasiri S, Luecha T, Chaithap C, Sawanyawisuth K. Which oropharyngeal factors are significant risk factors for obstructive sleep apnea? An age-matched study and dentist perspectives. Nat Sci Sleep. 2016; 8:215-219.

32. Kale SS, Kakodkar P, Shetiya SH. Assessment of oral findings of dental patients who screen high and no risk for obstructive sleep apnea (OSA) reporting to a dental college - A cross sectional study. Sleep Sci. 2018; 11(2):112-7.

33. Doneh B. Epworth Sleepiness Scale. Occup Med. 2015; 65(6):508-12.

34. Netzer N, Stoohs R, Netzer C, et al. Using the Berlin Questionnaire to identify patients at risk for the sleep apnea syndrome. Ann Intern Med. 1999; 131:485-91.

35. Chung F, Yegneswaran B, Liao $P$ et al. STOP questionnaire: $A$ tool to screen patients for obstructive sleep apnea. Anesthesiology. 2008;108: 812-21.

36. Jaradat M, Rahhal A. Obstructive Sleep Apnea, Prevalence, Etiology \& Role of Dentist \& Oral Appliances in Treatment: Review Article. Open Journal Of Stomatology. 2015;5:187-201.

37. Epstein E, Kristo D, Strollo Jr P. Clinical Guidelines for the Evaluation, Management and Long-term Care of Obstructive Sleep Apnea in Adults. J Clin Sleep Med. 2009;5:263-79.

38. Gay P, Weaver T, Loube D et al. Evaluation of positive airway pressure treatment for sleep related breathing disorders in adults. Sleep. 2006; 29:381-401. 39. Veasey S, Guilleminault C, Strohl K et al. Medical therapy for obstructive sleep apnea: a review by the Medical Therapy for Obstructive Sleep Apnea Task Force of the Standards of Practice Committee of the American Academy of Sleep Medicine. Sleep. 2006; 29:1036-44.

40. Lye K, Waite P, Meara D, et al. Quality of life evaluation of maxillomandibular advancement surgery for treatment of obstructive sleep apnea. J Oral Maxillofacial Surgery. 2008; 66:968-72.

41. Rivlin J, Hoffstein V, Kalbfleisch J, McNicholas W, Zamel N, Bryan AC. Upper airway morphology in patients with idiopathic obstructive sleep apnea. Am Rev Respir Dis. 1984; 129(3):355-6o.

42. Kushida CA, Morgenthaler TI, Littner MR, Alessi CA, Bailey D, Coleman J Jr et al. American Academy of Sleep. Practice parameters for the treatment of snoring and Obstructive Sleep Apnea with oral appliances: an update for 2005. Sleep. 2006; 29(2):240-3.

43. Barthlen GM, Brown LK, Wiland MR, Sadeh JS, Patwari J, Zimmerman M. Comparison of three oral appliances for treatment of severe obstructive sleep apnea syndrome. Sleep Med. 2000; 1(4):299-305.

44. Addy N, Bennett K, Blanton A, Dort L, Levine M, Postol K, Schell T, Schwartz D, Sheats R, Smith H. Policy statement on a dentist's role in treating sleeprelated breathing disorders. Journal of Dental Sleep Medicine. 2018; 5(1):25-6.

45. Maspero C, Giannini L, Galbiati G, Rosso G, Farronato G. Obstructive sleep apnea syndrome: a literature review. Minerva Stomatol. 2015; 64(2):97109.

46. Shah N, Bang A, Bhagat A. Indian research on sleep disorders. Indian J Psychiatry. 2010; 52(1):S255S259.

47. Sri Meenakshi R B, Senthil Kumar K P, Prabhakar $\mathrm{K}$. Evaluation of awareness of issues regarding obstructive sleep apnea and the orthodontist role in management: A survey among dental and medical practitioners. J Indian Acad Dent Spec Res. 2016; 3:436

48. Vigg A, Vigg A, Vigg A. Awareness of issues related to sleep disordered breathing amongst practicing physicians. Indian J Chest Dis Allied Sci. 2005;47(1):25-9.

\section{AUTHOR AFFILIATIONS:}

1. Professor and Head (ORCID iD: https://orcid.org/oooo-0003-3117-0312)

2. *PG Student (ORCID iD: https://orcid.org/oooo-0003-0442-7418)

3. Professor (ORCID: https://orcid.org/oooo-0oo3-0442-7418)

4. Senior Lecturer (ORCID iD: https://orcid.org/oooo-0oo2-9805-2436, Dr. Pratibha Taneja)

(ORCID iD: https://orcid.org/oooo-0002-7899-8603, Dr. Sakshi Kataria)

Department of Public Health Dentistry, Sudha Rustagi College of Dental Sciences and Research, Faridabad, Haryana

5. Dental Surgeon, Haryana Civil Medical Services 